\title{
Dietary patterns on weekdays and weekend days in 4-14-year-old Danish children
}

\author{
Berit W. Rothausen ${ }^{1 *}$, Jeppe Matthiessen ${ }^{1}$, Lene F. Andersen ${ }^{2}$, Per B. Brockhoff ${ }^{3}$ and Inge Tetens ${ }^{1}$ \\ ${ }^{1}$ Division of Nutrition, National Food Institute, Technical University of Denmark, Mørkhøj Bygade 19, DK-2860 Søborg, \\ Denmark \\ ${ }^{2}$ Department of Nutrition, Institute of Basic Medical Sciences, University of Oslo, PB 1046, Blindern, N-0316 Oslo, Norway \\ ${ }^{3}$ Department of Informatics and Mathematical Modeling, Technical University of Denmark, Richard Petersens Plads, \\ Building 321, DK-2800 Kongens Lyngby, Denmark
}

(Submitted 30 January 2012 - Final revision received 17 July 2012 - Accepted 17 July 2012 - First published online 10 September 2012)

\begin{abstract}
Little is known about dietary patterns on weekdays and weekend days in children, and the aim of the present study was to investigate 4-14-year-old children's dietary patterns specifically on weekdays (Monday-Thursday) and weekend days (Saturday-Sunday). Dietary data were derived from the Danish National Survey of Dietary Habits and Physical Activity 2003-8, where a total of 784 children aged 4-14 years completed a $7 \mathrm{~d}$ pre-coded food record. Principal component analysis was used to identify dietary patterns in the age groups 4-6, 7-10 and 11-14 years. Consistently, two dietary patterns, labelled 'processed' and 'health conscious', emerged on both weekdays and weekend days. Factor scores from corresponding dietary patterns were significantly correlated between weekdays and weekend days with the exception of the 'health conscious' pattern in the 7-10-year-olds. Within each age group, children with high agreement for the 'processed' pattern had a significantly higher dietary energy density, which was reflected in significantly higher intakes of sugarsweetened beverages and lower intakes of fruit and vegetables, compared with children with high agreement for the 'health conscious' pattern $(P<0 \cdot 05)$. Moreover, these variables indicated less healthy dietary intakes on weekend days than on weekdays for both patterns. In conclusion, two distinct dietary patterns, labelled 'processed' and 'health conscious', were identified on both weekdays and weekend days for each age group. While overall major dietary patterns may somewhat track between weekdays and weekends, the specific foods actually eaten became less healthy during weekends.
\end{abstract}

\section{Key words: Dietary assessments: Principal component analysis: Energy density}

Dietary habits play an important role for health, growth and development in children. Assessment of children's dietary habits is therefore essential in numerous aspects of nutritional research including the development of evidence-based initiatives for use in health promotion. Different approaches have been used to describe dietary habits depending on the study objectives and the quality of data available. Acknowledging that foods are eaten in combination, analyses of the overall dietary pattern may provide a more comprehensive approach to the assessment of dietary intake than simple descriptions of intake levels of individual foods or nutrients ${ }^{(1,2)}$.

The use of statistical methods to define dietary patterns in a population has facilitated more extensive analyses of dietary intake, and among the data-driven methods, principal component analysis (PCA) is a frequently used exploratory approach to identify dietary patterns. PCA allows inclusion of many food items and uses the correlations between a large number of variables to identify underlying dimensions in the data. In this way, PCA reduces the dimensionality of the data while retaining as much of the relevant information as possible by creating patterns of food intake ${ }^{(3)}$.

Although the use of dietary pattern analysis has been applied most widely in studies of adult populations, several dietary studies have investigated PCA-derived dietary patterns in children and the associations of these patterns with various health outcomes and socio-economic indicators ${ }^{(4-7)}$. Furthermore, PCA has been used to assess the stability of dietary patterns over time during childhood as well as in adulthood ${ }^{(8-11)}$.

Previous research in children has shown that snacking and other daily dietary habits differ on weekdays compared with

Abbreviations: High HCP, children with factor scores in the highest tertile for the 'health conscious' pattern and in the lowest or intermediate tertiles for the 'processed' pattern; High PP, children with factor scores in the highest tertile for the 'processed' pattern and in the lowest or intermediate tertiles for the 'health conscious' pattern; PCA, principal component analysis; SSB, sugar-sweetened beverages.

*Corresponding author: B. W. Rothausen, fax +453588 7119, email bewro@food.dtu.dk 
weekend days ${ }^{(12,13)}$. In our earlier study of Danish children, the intake of key food groups and the dietary energy density was found to differ significantly between weekdays and weekends ${ }^{(14)}$. It therefore seems obvious to consider energy density in relation to dietary intakes between weekdays and weekends further. Little is known about dietary patterns on weekdays and weekends in children, and to the authors' knowledge, no study has used PCA to investigate the dietary patterns that emerge specifically on weekdays and weekend days. As a more holistic approach may provide new insights to this issue, the aim of the present study was to investigate dietary patterns obtained by use of PCA on weekdays and weekend days in a representative sample of Danish children, 4-14 years of age.

\section{Methods}

\section{Sample}

The present study is based on data from the Danish National Survey of Dietary Habits and Physical Activity 2003-8, which is a nationwide, representative cross-sectional survey. The survey was ongoing, with all seasons being equally represented. The study population comprised a simple random sample of 4-14-year-old children, retrieved from the Central Office of Civil Registration. In comparison with census data from Statistics Denmark, the distribution of sex and age of the participants could be characterised as representative for the Danish population of children aged $4-14$ years.

\section{Dietary intake}

Dietary intake was recorded every day for seven consecutive days in food diaries with pre-coded response categories, which included open-answer options. Children and their parents were instructed in person by trained interviewers on how to complete the food diaries. The parents were responsible for completing the diaries and for deciding to what extent their children were capable of assisting. The food record was organised according to the typical Danish meal pattern (breakfast, lunch, dinner and in-between meals). Each meal was divided into sections with headings such as beverages, bread, spreadable fats, meat and vegetables to make it easier to find and record the relevant foods, dishes and beverages. For food items not included in the pre-coded food record, the participants wrote the type of food and portion size eaten in open-answer categories. The quantities of foods consumed were given in predefined household measures (cups, spoons, slices, etc.) or estimated from photos in a picture book containing fourteen food photograph series, each series showing four to six different portion sizes. Participants also received a food-recording booklet for the children to take to school or to other places outside their home on the days of assessment as a supplement to the food record. Data were scanned using The Eyes \& Hands program (version 5.2, 2005; Readsoft Limited). Intakes of energy, nutrients and food items were calculated for each individual using the software system GIES (version 0.995a; developed at the National Food Institute, Technical University of Denmark), and the Danish Food Composition Databank (version 7; http://www. foodcomp.dk). Validation of the method for children and adults has been described elsewhere ${ }^{(15,16)}$.

The present study was conducted according to the guidelines laid down in the Declaration of Helsinki and was approved by the Danish Data Protection Agency. The Danish National Committee on Health Research Ethics decided that the Danish National Survey of Dietary Habits and Physical Activity did not require their approval. Written informed consent was obtained from all participants.

Before conducting the PCA, dietary intake data were aggregated into a total of thirty-two food groups based on relevant similarities in the type of food and macronutrient composition. Certain food items that were only consumed sporadically (alcoholic beverages, coffee and tea) were excluded from the analyses. Furthermore, energy density $(\mathrm{kJ} / 100 \mathrm{~g})$ of the diet was calculated for solid food and liquids consumed as food (for example, soups and yogurt). Energy density was included in the PCA together with the other dietary variables, as it may provide an indication of the diet quality and is of importance in relation to energy balance $^{(17,18)}$.

\section{Weight status}

Information about height and weight was obtained through a personal face-to-face interview with one of the parents, referred to as the responding parent, who was the mother in $87 \%$ of the cases. Prevalence of overweight and obesity in the study sample was defined according to international age- and sex-specific BMI cut-off values for children and adolescents $^{(19)}$ corresponding to BMI values of 25 and $30 \mathrm{~kg} / \mathrm{m}^{2}$, respectively, for adults aged $\geq 18$ years.

\section{Parental education}

The educational level of the responding parent was defined in four categories: (1) basic school (10 years or less of total education); (2) vocational education, upper secondary school (10-12 years); (3) short higher education (13-15 years); (4) long higher education $(15+$ years $)$. No information about the educational level of the other parent was obtained in the present study.

\section{Definition of weekdays and weekend days}

From analyses of dietary habits in the same sample of Danish children, it was previously found that the dietary intakes on Fridays appeared as a mix of the diet on the other weekdays (Monday to Thursday) and weekend days (Saturday to Sunday) $)^{(14)}$. In order to obtain more distinct patterns and strengthen the present analyses, weekdays were defined as Monday to Thursday and weekend days as Saturday to Sunday. 


\section{Statistical analysis}

Due to the wide age range of children in the study population and associated different degrees of parental influence on the diet and diet recording, the main analyses were performed separately for the three age groups 4-6, 7-10 and 11-14 years $^{(20)}$. Differences between sex regarding height, weight and BMI were analysed using Student's $t$ test, whereas differences between the age groups regarding height, weight and BMI were analysed using one-way ANOVA and Tukey's post hoc test. Differences regarding parental education and weight status were assessed between sex and between the age groups using the $\chi^{2}$ test and Fisher's exact test.

Dietary patterns were identified for each age group on weekdays and weekend days by use of PCA with varimax rotation $^{(21)}$. Whether to adjust for energy intake before entering foods into a PCA is a matter of debate ${ }^{(22)}$, and the initial analyses for the present study were conducted with and without adjustment for energy, which showed somewhat similar tendencies. However, the patterns obtained using the unadjusted values seemed to appear slightly more clearly defined, and the further analyses were conducted on the mean intake $(\mathrm{g} / \mathrm{d})$.

PCA sequentially creates linear combinations, called components, of the input variables that exhibit maximal possible variance. Used on a correlation matrix, it is a way to explain the overall correlation structure by a few key components, and with dietary data, the components can be perceived as dietary patterns. The correlations of each food item with a dietary pattern are called component loadings. A negative value of a component loading indicates an inverse impact on the pattern. Food variables with component loadings $>0.2$ or $<-0.2$ were considered to have a strong association with the corresponding pattern, and were used to identify and label the specific dietary patterns. The labels summarise characteristic features of the patterns that are general for all three age groups, although some variation in the patterns occurred between the age groups. The chosen number of patterns on weekdays and weekend days was primarily based on examination of the scree plots, and the interpretability of the components. The effect of adding or removing one or more components was also assessed; however, for all three age groups, a solution with two patterns ('processed' and 'health conscious') was considered as best representing the data.

For each child, a factor score for each of the patterns was calculated. The factor score indicates how closely the child's individual dietary pattern is in agreement with the overall dietary pattern. Positive factor scores indicate higher consumption of the positively loaded food items in a given dietary pattern, while negative factor scores indicate low consumption of the positively loaded food items (and vice versa for the negatively loaded food items).

The derived factor scores were all approximately normally distributed. Pearson's correlation coefficients between these factor scores were calculated to assess the associations between dietary patterns on weekdays and weekend days. Furthermore, the factor scores were used to define groups of children with high agreement for each pattern. In each age group, the children were divided into tertiles for each of the two dietary patterns based on their individual factor scores for the relevant pattern. To clarify further the possible differences between the patterns, groups of children with high agreement for a pattern and also low or intermediate agreement for the other pattern were defined. Thus, within each age group, the group of children with factor scores in the highest tertile for the 'processed' pattern and factor scores in the lowest or intermediate tertiles for the 'health conscious' pattern was named 'High PP'. The group of children with factor scores in the highest tertile for the 'health conscious' pattern and in the lowest or intermediate tertiles for the 'processed' pattern was named 'High HCP'.

Energy density and intake of fruit and vegetables, sugarsweetened beverages (SSB) and sweets and chocolate on weekdays and weekend days were compared between the 'High PP' and 'High HCP' groups in each age group using Student's $t$ test. These variables were selected on the basis of key findings from previous analyses based on indicator variables on weekdays and weekend days in the same population of Danish children ${ }^{(14)}$. Differences between the 'High PP' and 'High HCP' groups regarding the distribution of sex, weight status and parental educational level were tested using Fisher's exact test.

Data were analysed with the Statistical Package for the Social Sciences software (version 19; IBM SPSS Statistics, Inc.). Statistical differences were considered significant at $P<0.05$.

Table 1. Characteristics of the study population

(Mean values and standard deviations or percentages)

\begin{tabular}{|c|c|c|c|}
\hline & $\begin{array}{l}4-6 \text { years } \\
(n 207) \%\end{array}$ & $\begin{array}{c}7-10 \text { years } \\
(n 287) \%\end{array}$ & $\begin{array}{c}11-14 \text { years } \\
(n 290) \%\end{array}$ \\
\hline \multicolumn{4}{|l|}{ Sex } \\
\hline Boys & 50 & 53 & 47 \\
\hline Girls & 50 & 47 & 53 \\
\hline \multicolumn{4}{|l|}{ Height (cm) } \\
\hline Mean & 118 & 139 & 161 \\
\hline $\mathrm{SD}$ & 9 & 9 & 10 \\
\hline \multicolumn{4}{|l|}{ Weight (kg) } \\
\hline Mean & $22 \cdot 0$ & $32 \cdot 8$ & $49 \cdot 9$ \\
\hline SD & 4.3 & 7.5 & $10 \cdot 7$ \\
\hline \multicolumn{4}{|l|}{ BMI $\left(\mathrm{kg} / \mathrm{m}^{2}\right)$} \\
\hline Mean & $15 \cdot 6$ & $16 \cdot 8$ & $19 \cdot 1$ \\
\hline SD & 1.9 & $2 \cdot 6$ & $3 \cdot 0$ \\
\hline \multicolumn{4}{|l|}{ Weight status* } \\
\hline \multicolumn{4}{|l|}{ Overweight } \\
\hline Boys & $8 \cdot 7$ & $13 \cdot 8$ & $17 \cdot 8$ \\
\hline Girls & $15 \cdot 5$ & $14 \cdot 1$ & $14 \cdot 2$ \\
\hline \multicolumn{4}{|l|}{ Obese } \\
\hline Boys & 0 & 3.9 & 3.0 \\
\hline Girls & 3.9 & 4.4 & $3 \cdot 2$ \\
\hline \multicolumn{4}{|l|}{ Parental education $\dagger$} \\
\hline Basic school & $8 \cdot 7$ & 8.7 & $11 \cdot 7$ \\
\hline Vocational education & 41.5 & 43.9 & $42 \cdot 4$ \\
\hline Short higher education & $8 \cdot 2$ & $10 \cdot 1$ & 14.5 \\
\hline Long higher education & 41.5 & $37 \cdot 3$ & 31.4 \\
\hline $\begin{array}{l}\text { *Weight status according } \\
\text { proportions of overweight c } \\
\text { Parental educational level: } \\
\text { vocational education, uppe } \\
\text { cation ( } 13-15 \text { years, prim } \\
\text { primarily theoretical). }\end{array}$ & $\begin{array}{l}\text { international } \\
\text { dren do not inc } \\
\text { asic school }(10 \\
\text { econdary scho }\end{array}$ & $\begin{array}{l}\text { ut-off values }{ }^{(19} \\
\text { de obese childre } \\
\text { years or less } \\
(10-12 \text { years) }\end{array}$ & $\begin{array}{l}\text { The presented } \\
\text { otal education); } \\
\text { hort higher edu- } \\
\text { on (15+ years, }\end{array}$ \\
\hline
\end{tabular}




\section{Results}

\section{Study population}

A total of 1294 children were invited to participate and 1006 (78\%) children accepted. After exclusion of incomplete dietary recordings, data from 784 (61\%) children with seven consecutive days of dietary recording and information about BMI and parental educational level were available for analysis. The characteristics of the study population are presented in Table 1. There were no significant differences between the age groups regarding weight status as overweight or obese and parental education. Within each age group, no sex differences were found regarding height, weight, BMI, weight status as overweight or obese and parental education. On a weekly basis, boys had a significantly higher mean total energy intake than girls in all three age groups (4-6 years: boys $7 \cdot 87$ $(\mathrm{SD} 1.87) \mathrm{MJ} / \mathrm{d} v$. girls $6.91(\mathrm{SD} 1.34) \mathrm{MJ} / \mathrm{d}, \quad P<0.001 ; 7-10$ years: boys 8.79 (SD 1.94) $\mathrm{MJ} / \mathrm{d} v$. girls $8.19(\mathrm{SD} 2.03) \mathrm{MJ} / \mathrm{d}$, $P=0 \cdot 01 ; 11-14$ years: boys 9.57 (sD $2 \cdot 83) \mathrm{MJ} / \mathrm{d} v$. girls $7 \cdot 74$ (sD 1.99$) \mathrm{MJ} / \mathrm{d}, P<0.001$ ).

\section{Dietary patterns}

In all three age groups, two distinct dietary patterns were identified on both weekdays and weekend days. The patterns were labelled 'processed' and 'health conscious' based on the general characteristics of the foods with the highest component loadings within each pattern. The dietary variables with high loadings $(>0 \cdot 2$ or $<-0 \cdot 2)$ on these patterns are presented in Tables 2-4. The patterns differed slightly between the age groups and between weekdays and weekend days; however, consistently for all age groups and periods, the principal component labelled 'processed' was characterised by high positive loadings for energy density, white bread, fat on bread, and jam, honey and chocolate spreads on both weekdays and weekend days. SSB, cakes and biscuits and sweets and chocolate also had high loadings in the 'processed' pattern on both weekdays and weekend days for all age groups, except for weekend days in the 4-6-year-olds. The other principal component labelled 'health conscious' was consistently characterised by high loadings for fruit, vegetables and water on both weekdays and weekend days for all age groups, whereas the other variables with high component loadings in the 'health conscious' pattern varied to some extent between the age groups.

Pearson's correlation coefficients between the factor scores from each dietary pattern showed significant positive correlations between the corresponding patterns on weekdays and weekends with the exception of the 'health conscious' pattern in the 7-10-year-olds (Table 5). Overall, correlation coefficients for the 'processed' pattern were slightly higher than those for the 'health conscious' pattern.

Comparisons of the 'High PP' group with the 'High HCP' group (i.e. groups of children with factor scores in the highest tertile for one pattern and factor scores in the lowest or intermediate tertile for the other pattern) showed that energy

Table 2. Variables of foods $(\mathrm{g} / \mathrm{d})$ and energy density $(\mathrm{kJ} / 100 \mathrm{~g})$ with loadings $>|0 \cdot 2|$ for the two dietary patterns in children aged $4-6$ years $(n 207)^{*}$

\begin{tabular}{|c|c|c|c|c|}
\hline \multirow[b]{2}{*}{ Food items } & \multicolumn{2}{|c|}{ 'Processed' pattern } & \multicolumn{2}{|c|}{ 'Health conscious' pattern } \\
\hline & Weekdays & Weekend days & Weekdays & Weekend days \\
\hline White bread & 0.61 & 0.45 & & -0.34 \\
\hline Energy density & 0.60 & 0.37 & -0.58 & -0.80 \\
\hline Fats on bread & 0.55 & 0.76 & & \\
\hline Jam, honey and chocolate spreads & 0.55 & 0.47 & & \\
\hline Cold cuts & 0.48 & 0.64 & 0.43 & 0.24 \\
\hline Beverages, sugar sweetened & 0.41 & & -0.30 & -0.25 \\
\hline Rye bread & 0.36 & 0.55 & 0.53 & 0.31 \\
\hline Sweets and chocolate & 0.34 & & -0.22 & -0.34 \\
\hline Sauce and gravy & 0.31 & 0.39 & 0.21 & \\
\hline Cakes and biscuits & 0.29 & & -0.27 & -0.32 \\
\hline Juice & 0.27 & & & \\
\hline Dairy products, fat $\dagger$ & 0.22 & 0.23 & & \\
\hline Potatoes & 0.21 & 0.31 & 0.37 & \\
\hline Oatmeal & -0.24 & & & 0.26 \\
\hline Water & & 0.25 & 0.56 & 0.43 \\
\hline Vegetables & & & 0.51 & 0.48 \\
\hline Fruit & & & 0.50 & 0.61 \\
\hline Dairy products, low fatł & & & 0.23 & 0.34 \\
\hline Red meat, fat & & & 0.23 & 0.21 \\
\hline Nuts and dried fruits & & & 0.32 & \\
\hline Salty snacks & & & -0.23 & -0.22 \\
\hline Fast foods & & & -0.32 & -0.23 \\
\hline Coarse bread and crisp bread & & & & 0.30 \\
\hline Variation explained (\%) & $7 \cdot 8$ & 7.5 & 7.9 & $8 \cdot 1$ \\
\hline
\end{tabular}

${ }^{*}$ Food groups with component loadings $<|0.2|$ for both principal components included beverages, light; coarse bread and crisp bread; fish and seafood; French fries; ice cream and desserts; juice; nuts and dried fruits; other breakfast cereals than oatmeal; pies and egg dishes; poultry; red meat, lean; rice, pasta and polenta; soups.

†Dairy products with $\geq 1.5 \%$ fat

$\ddagger$ Dairy products with $<1.5 \%$ fat. 
Table 3. Variables of foods $(\mathrm{g} / \mathrm{d})$ and energy density $(\mathrm{kJ} / 100 \mathrm{~g})$ with loadings $>|0 \cdot 2|$ for the two dietary patterns in children aged $7-10$ years $(n 287)^{\star}$

\begin{tabular}{|c|c|c|c|c|}
\hline \multirow[b]{2}{*}{ Food items } & \multicolumn{2}{|c|}{ 'Processed' pattern } & \multicolumn{2}{|c|}{ 'Health conscious' pattern } \\
\hline & Weekdays & Weekend days & Weekdays & Weekend days \\
\hline White bread & 0.65 & 0.40 & & \\
\hline Energy density & 0.47 & 0.84 & -0.76 & \\
\hline Sweets and chocolate & 0.44 & 0.22 & & \\
\hline Jam, honey and chocolate spreads & 0.43 & 0.33 & & \\
\hline Beverages, sugar sweetened & 0.37 & 0.28 & & \\
\hline Salty snacks & 0.37 & & & \\
\hline Cakes and biscuits & 0.34 & 0.23 & & \\
\hline Red meat, fat & 0.29 & & 0.28 & 0.53 \\
\hline Fast foods & 0.29 & & & -0.41 \\
\hline Juice & 0.28 & & 0.30 & \\
\hline Fats on bread & 0.23 & 0.47 & -0.35 & 0.28 \\
\hline Cold cuts & -0.27 & & -0.34 & 0.49 \\
\hline Oatmeal & -0.31 & -0.26 & & \\
\hline Dairy products, low fat $†$ & -0.36 & -0.27 & & 0.25 \\
\hline Other breakfast cereals $\ddagger$ & -0.37 & -0.25 & & \\
\hline Rye bread & -0.39 & & -0.26 & 0.51 \\
\hline French fries & & 0.28 & & \\
\hline Soup & & -0.22 & & \\
\hline Water & & -0.23 & 0.37 & 0.30 \\
\hline Nuts and dried fruits & & -0.27 & 0.33 & 0.22 \\
\hline Vegetables & & -0.49 & 0.62 & 0.39 \\
\hline Fruit & & -0.62 & 0.72 & 0.31 \\
\hline Potatoes & & & & 0.57 \\
\hline Sauce and gravy & & & & 0.46 \\
\hline Fish and seafood & & & & 0.33 \\
\hline Ice cream and desserts & & & 0.21 & \\
\hline Beverages, light & & & -0.32 & \\
\hline Variation explained (\%) & 7.5 & 7.9 & 8.0 & $7 \cdot 1$ \\
\hline
\end{tabular}

density of the diet as well as intake of sweets and chocolate and SSB were significantly higher, whereas intake of fruit and vegetables was significantly lower in the 'High PP' group than in the 'High HCP' groups $(P<0.05$; Table 6). These differences were evident on both weekdays and weekend days for all age groups, except for intake of sweets and chocolate on weekend days in the 7-10-year-olds. Moreover, the differences between the 'High PP' and 'High HCP' groups seemed slightly amplified on weekend days compared with weekdays.

No significant differences regarding BMI, weight status, sex and parental educational level were found between the 'High PP' and 'High HCP' groups within each age group (data not shown).

\section{Discussion}

In the present sample of Danish children, two dietary patterns labelled 'processed' and 'health conscious' were identified on both weekdays and weekend days. Although not completely identical, these dietary patterns were consistently found in all three age groups. The shared characteristics for the "processed' pattern on both weekdays and weekend days in all age groups were high loadings for energy density and white bread, fat on bread, and jam, honey and chocolate spreads, whereas the shared characteristics of the 'health conscious' pattern were high loadings for fruit, vegetables and water. Energy density, which was included in the identification of dietary patterns as an overall indicator of the diet quality, loaded highly on the 'processed' pattern, thus, indicating that this dietary pattern is characterised by a high dietary energy density and an overall lower dietary quality.

The results of the present study showed that, in general, factor scores from the corresponding dietary patterns on weekdays and weekend days were significantly positively correlated. No significance was observed for the 'health conscious' pattern in the 7-10-year-olds; however, there is no obvious explanation for this finding. The initial analyses with varying numbers of included food groups did not show a tendency for the patterns of this age group to differ from the patterns of the other age groups. The lower correlations between the corresponding dietary patterns that are presented for this age group seem rather to be an exception to the general findings. Although not completely consistent, the present results suggest that overall major dietary patterns may somewhat track between weekends and weekdays, while the specific foods actually eaten became less healthy during weekends.

PCA has previously been used to assess the stability of dietary patterns during periods of several months to years in 
Table 4. Variables of foods $(\mathrm{g} / \mathrm{d})$ and energy density $(\mathrm{kJ} / 100 \mathrm{~g})$ with loadings $>|0 \cdot 2|$ for the two dietary patterns in children aged $11-14$ years $(n 290)^{*}$

\begin{tabular}{|c|c|c|c|c|}
\hline \multirow[b]{2}{*}{ Food items } & \multicolumn{2}{|c|}{ 'Processed' pattern } & \multicolumn{2}{|c|}{ 'Health conscious' pattern } \\
\hline & Weekdays & Weekend days & Weekdays & Weekend days \\
\hline Energy density & 0.74 & 0.81 & -0.40 & \\
\hline Fats on bread & 0.66 & 0.48 & 0.31 & 0.52 \\
\hline Jam, honey and chocolate spreads & 0.60 & 0.45 & & \\
\hline White bread & 0.41 & 0.55 & & \\
\hline Cold cuts & 0.34 & & 0.54 & 0.56 \\
\hline Beverages, light & 0.29 & 0.21 & & \\
\hline Rye bread & 0.28 & & 0.60 & 0.59 \\
\hline Cakes and biscuits & 0.26 & 0.26 & & \\
\hline Sweets and chocolate & 0.25 & 0.24 & & \\
\hline Juice & 0.24 & & & 0.39 \\
\hline French fries & 0.23 & & & \\
\hline Poultry & 0.23 & & & \\
\hline Vegetables & -0.25 & -0.37 & 0.59 & 0.32 \\
\hline Fruit & -0.29 & -0.44 & 0.23 & 0.42 \\
\hline Soup & -0.32 & & & \\
\hline Other breakfast cereals & -0.40 & -0.27 & & \\
\hline Red meat, fat & & 0.23 & 0.32 & \\
\hline Potatoes & & & 0.57 & \\
\hline Sauce and gravy & & & 0.38 & \\
\hline Water & & & 0.32 & 0.47 \\
\hline Dairy products, fat $\dagger$ & & & 0.29 & 0.31 \\
\hline Nuts and dried fruits & & & 0.29 & \\
\hline Fish and seafood & & & 0.25 & \\
\hline Fast foods & & & -0.32 & \\
\hline Salty snacks & & & -0.24 & \\
\hline Coarse bread and crisp bread & & & & 0.46 \\
\hline Variation explained (\%) & 8.0 & $7 \cdot 1$ & 7.9 & 6.5 \\
\hline
\end{tabular}

${ }^{*}$ Food groups with component loadings $<|0.2|$ for both principal components included beverages, light; coarse bread and crisp bread; dairy products, low fat $(\leq 1.5 \%)$; fast food; fish and seafood; French fries; ice cream and desserts; nuts and dried fruits; oatmeal; pies and egg dishes; potatoes; poultry; red meat, lean; rice, pasta and polenta; salty snacks; sauce and gravy; soups.

† Dairy products with $\geq 1.5 \%$ fat.

childhood, adolescence and adulthood ${ }^{(8-10,23-25)}$. Types and numbers of patterns comparable with the present findings have been found in other studies in children and adolescents, including patterns with similarities to the 'processed' and 'health conscious' patterns ${ }^{(6,23)}$. Other studies that have examined stability of dietary patterns over time using correlations have identified patterns on the basis of estimates of usual consumption including both weekdays and weekend days. Findings from these studies have shown similar or somewhat higher correlations between the corresponding patterns $^{(10,26,27)}$. However, since this is the first study to assess dietary patterns obtained using PCA specifically on weekdays and weekend days, these results are not directly comparable with those of other studies.

Some general environmental and structural differences between school days and non-school days may in part explain the findings that the dietary quality is lower on weekend days. School days may be more structured and supervised, while parents' attitudes towards healthy eating habits and the availability of different foods and beverages during weekends are most probably a very important factor for the variation in dietary quality during the week ${ }^{(28)}$.

In the same study population, a tendency of a lower diet quality on weekend days compared with weekdays has previously been presented ${ }^{(14)}$. These findings combined imply that subgroups with differences in dietary habits of nutritional concern exist, and that these differences are maintained on weekdays as well as on weekend days. This notion was further supported by the findings of significant and health-relevant differences in the energy density of the diet and in intakes of fruit and vegetables, SSB and sweets and chocolate, when comparing the 'High PP' group with the 'High HCP' group (i.e. comparing groups of children with high agreement for the 'processed pattern' with groups of children with high agreement for the 'health conscious' pattern). These results were found for both weekdays and weekend days with minor differences between the age groups. Moreover, within each of the 'High PP' and 'High HCP' groups, a significantly

Table 5. Pearson's correlation coefficients $(r)$ between the factor scores obtained on weekdays and weekend days in the 4-6-, 7-10- and 11-14-year-old children

(Pearson's correlation coefficients and 95\% confidence intervals)

\begin{tabular}{|c|c|c|c|c|}
\hline & \multicolumn{2}{|c|}{$\begin{array}{l}\text { 'Processed' } \\
\text { pattern }\end{array}$} & \multicolumn{2}{|c|}{$\begin{array}{l}\text { 'Health conscious' } \\
\text { pattern }\end{array}$} \\
\hline & \multicolumn{2}{|c|}{$\begin{array}{l}\text { Weekdays } v \text {. } \\
\text { weekend days }\end{array}$} & \multicolumn{2}{|c|}{$\begin{array}{l}\text { Weekdays } v \text {. } \\
\text { weekend days }\end{array}$} \\
\hline & $r$ & $95 \% \mathrm{Cl}$ & $r$ & $95 \% \mathrm{Cl}$ \\
\hline $4-6$ years $(n 207)$ & 0.34 & $0.21,0.45$ & 0.32 & $0.19,0.43$ \\
\hline $7-10$ years $(n 287)$ & 0.17 & $0.05,0.28$ & 0.09 & $-0.02,0.21$ \\
\hline $11-14$ years $(n 290)$ & 0.48 & $0.39,0.56$ & 0.35 & $0.28,0.45$ \\
\hline
\end{tabular}


Table 6. Mean intakes of energy density (kJ/100 g) and selected foods ( $/ \mathrm{d}$ ) on weekdays and weekend days for the 'High PP'* and 'High HCP' $\dagger$ groups within each age group (Median values and 5th and 95th percentiles $\left(P_{5}\right.$ and $\left.P_{95}\right)$ )

\begin{tabular}{|c|c|c|c|c|c|c|c|c|c|c|c|c|c|c|}
\hline & \multicolumn{6}{|c|}{ Weekdays } & \multirow[b]{3}{*}{$P \neq$} & \multicolumn{6}{|c|}{ Weekend days } & \multirow[b]{3}{*}{$P \ddagger$} \\
\hline & \multicolumn{3}{|c|}{ 'High PP' } & \multicolumn{3}{|c|}{ 'High HCP' } & & \multicolumn{3}{|c|}{ 'High PP' } & \multicolumn{3}{|c|}{ 'High HCP' } & \\
\hline & Median & $P_{5}$ & $\mathrm{P}_{95}$ & Median & $P_{5}$ & $P_{95}$ & & Median & $P_{5}$ & $P_{95}$ & Median & $P_{5}$ & $P_{95}$ & \\
\hline $4-6$ years & & & & $n 46$ & & & & & & & $n 44$ & & & \\
\hline Energy density§ & 848 & 668 & 1148 & 570 & 501 & 768 & $<0.001$ & 999 & 767 & 1445 & 617 & 473 & 839 & $<0.001$ \\
\hline Fruit and vegetables & 147 & 19 & 387 & 382 & 184 & 735 & $<0.001$ & 85 & 0 & 401 & 331 & 93 & 685 & $<0.001$ \\
\hline Sweets and chocolate§ & 7 & 0 & 42 & 2 & 0 & 20 & 0.001 & 25 & 0 & 108 & 10 & 0 & 41 & 0.002 \\
\hline SSB\| & 113 & 0 & 744 & 0 & 0 & 244 & $<0.001$ & 272 & 0 & 750 & 100 & 0 & 513 & 0.001 \\
\hline $7-10$ years & & & & $n 67$ & & & & & & & $n 58$ & & & \\
\hline Energy density§ & 832 & 684 & 1121 & 571 & 402 & 701 & $<0.001$ & 1056 & 913 & 1301 & 740 & 447 & 935 & $<0.001$ \\
\hline Fruit and vegetables & 155 & 31 & 327 & 427 & 194 & 1051 & $<0.001$ & 55 & 0 & 216 & 313 & 102 & 1196 & $<0.001$ \\
\hline Sweets and chocolate $\S$ & 13 & 0 & 53 & 6 & 0 & 34 & 0.003 & 15 & 0 & 81 & 15 & 0 & 81 & 0.454 \\
\hline SSB§ & 163 & 0 & 1100 & 100 & 0 & 323 & $<0.001$ & 350 & 0 & 1300 & 263 & 0 & 805 & 0.047 \\
\hline $11-14$ years & & & & $n 64$ & & & & & & & $n 66$ & & & \\
\hline Energy density§ & 894 & 748 & 1152 & 638 & 437 & 823 & $<0.001$ & 1053 & 788 & 1382 & 720 & 453 & 981 & $<0.001$ \\
\hline Fruit and vegetables & 100 & 0 & 371 & 348 & 84 & 753 & $<0.001$ & 64 & 0 & 203 & 383 & 86 & 947 & $<0.001$ \\
\hline Sweets and chocolate\|l & 22 & 0 & 135 & 5 & 0 & 47 & $<0.001$ & 31 & 0 & 159 & 13 & 0 & 91 & 0.003 \\
\hline SSB§ & 213 & 0 & 738 & 50 & 0 & 919 & 0.011 & 400 & 0 & 1100 & 125 & 0 & 1278 & 0.013 \\
\hline
\end{tabular}

SSB, sugar-sweetened beverages.

*Children with factor scores in the highest tertile for the 'processed' pattern and in the lowest or intermediate tertiles for the 'health conscious' pattern.

† Children with factor scores in the highest tertile for the 'health conscious' pattern and in the lowest or intermediate tertiles for the 'processed' pattern.

$\mp$ Comparing the 'High PP' group with the 'High HCP' group.

$\S$ Values were significantly different between weekdays and weekend days for both the 'High PP' and 'High HCP' groups $(P<0.05)$.

II Values were significantly different between weekdays and weekend days for the 'High HCP' group $(P<0.05)$. 
higher energy density was observed on weekend days than on weekdays. This was also reflected in several of the selected key variables with overall tendencies of lower intakes of fruit and vegetables and higher intakes of SSB and sweets and chocolate.

Similar findings for certain key variables have been presented previously in studies of children ${ }^{(12,13)}$, and the tendency towards less healthy dietary habits during weekends compared with weekdays is also in accordance with other studies in pre-school children ${ }^{(29-31)}$. This detection of significantly unfavourable dietary patterns during weekends points at a considerable potential for dietary improvement, and the present findings suggest that focusing attention on the differences between weekdays and weekend days could prove useful for enhancing public health initiatives.

The World Cancer Research Foundation and the American Institute for Cancer Research recommend the average energy density of diets to be lowered towards approximately $525 \mathrm{~kJ} / 100 \mathrm{~g}$ excluding beverages ${ }^{(32)}$. In light of this, the observed differences in energy density between the 'High PP' and 'High HCP' groups were considerable, and especially high on weekend days where the median energy density was of $617-740 \mathrm{~kJ} / 100 \mathrm{~g}$ in the 'HCP' group and as high as about $1000 \mathrm{~kJ} / 100 \mathrm{~g}$ in the 'High PP' group. In line with this, intake of fruit and vegetables in the 'High PP' group was substantially below the recommended levels $(100-147 \mathrm{~g} / \mathrm{d}$ on weekdays and $55-85 \mathrm{~g} / \mathrm{d}$ on weekend days), whereas intake of SSB was high $(113-213 \mathrm{~g} / \mathrm{d}$ on weekdays and $272-400 \mathrm{~g} / \mathrm{d}$ on weekend days).

High levels of dietary energy density are of concern from a public health perspective as there is convincing evidence that a high intake of energy-dense foods, high in fat, added sugars or starch, promotes weight gain and overweight ${ }^{(17)}$. Furthermore, high energy density levels of the diet have been associated with lower dietary quality in both children ${ }^{(18)}$ and adults ${ }^{(33)}$. The present results as well as previous analyses of the diet in this sample of children substantiate these findings, and underscore the need for improvement of dietary habits especially in children with a high intake of energydense foods and a low intake of fruit and vegetables, and especially to focus on the dietary intake on weekends ${ }^{(14)}$.

\section{Methodological issues}

As with other methods, there are several methodological issues of the use of $\mathrm{PCA}^{(3,34)}$ and results should be interpreted in the light of this. PCA has the advantage of combining food items across the diet, and may provide a useful approach for summarising extensive dietary data into fewer interpretable combinations, thereby taking into account the complexity of the diet. However, although the PCA method is a datadriven method that explores existing dietary patterns without preconceived patterns, it is a major consideration that it involves subjective decisions that can influence the final interpretation. This includes, for example, preselecting and aggregation of food items into food groups, determining the value of component loadings considered to have a strong association with the patterns, the number of patterns to retain and the labelling of each pattern ${ }^{(1,34)}$. These decisions may make the results less data-driven than assumed theoretically. Also, the comparability with other studies is limited by the differences between studies regarding data treatment and interpretation of the analyses.

Inherently, the results represent the optimal model with respect to the explained proportion of variability between individuals. The two dietary patterns identified for each age group only accounted for 13.6-15.9\% of the variance; however, it is a general finding that dietary patterns derived using PCA account for only a small amount of the total variance $^{(34)}$. When interpreting a limited number of dietary patterns, as is often the case, caution should be taken as other patterns also exist within the dataset, although each of these explains progressively less of the variance than the first emerging patterns. Furthermore, if all participants have a high intake of a certain food item or food group, this will not appear as an important part of any pattern. It seems therefore useful to combine the findings from PCA with other analyses of the diet, depending on the study objectives, to support and extend the dietary pattern analyses. In that way, PCA and traditional nutritional analysis can be seen as complementary approaches that can be used together. Additionally, validity of the dietary patterns and results could be strengthened if a second method of extracting dietary patterns is used.

In the present analyses, the dietary intake data were included as means over 4 and $2 \mathrm{~d}$, respectively. Day-to-day variation is therefore larger in the weekend data than in the weekday data. However, the potential influence of this in the PCA is considered to be of minor importance. Only differences in individual day-to-day structures, or correlations between these that are different from the overall correlations could change the interpretability of the PCA-derived patterns.

As for all other dietary assessment studies, a limitation of the present study is that the self-reported food recording may potentially be subject to misreporting. In dietary assessment in children, the use of the parent report of a child's diet may also be seen as a limitation. However, the degree of underreporting seemed to be rather limited in the present sample, with the exception of the group of children aged 11-14 years $^{(14)}$, which is recognised as a particularly challenging age group when assessing dietary intake. Thus, there is a higher risk of misreporting in the dietary intake data from the 11-14-year-olds compared with the youngest age groups. Separate analyses for each sex were not conducted due to the limited sample sizes in each age group, and specific sex differences were therefore not part of the scope of the present paper.

The strengths of the present study include the comprehensive dietary data, for which each of the participants has provided daily recordings of dietary intake for $7 \mathrm{~d}$, which allowed us to analyse dietary patterns across the week. PCA has been applied on data from different dietary assessment methods, with FFQ as one of the primary dietary assessment methods; however, the patterns generated have generally been similar despite the dietary assessment method 
used $^{(3,35)}$. Furthermore, the strengths lie in the nationwide character of the study, as it is based on a nationally representative study and in the wide age span of the sample that render the results more generalisable to children in the general Danish population.

\section{Conclusion}

In the present sample of Danish children, two distinct dietary patterns, labelled 'processed' and 'health conscious', were identified on both weekdays and weekend days for each of the age groups 4-6, 7-10 and 11-14 years. While overall major dietary patterns may somewhat track between weekdays and weekends, the specific foods actually eaten became less healthy during weekends.

\section{Acknowledgements}

This study was supported by university PhD scholarships under DTU Food, Technical University of Denmark. The authors are grateful to researcher Anja Biltoft-Jensen, senior advisor Sisse Fagt and senior researcher Margit Velsing Groth who are responsible for the design and development of questionnaires to the Danish National Survey of Dietary Habits and Physical Activity. The authors are also grateful to senior advisor Tue Christensen, dietitian Karin Hess Ygil, data scanning manager Hanne-Jette Hinch and data warehouse manager Karsten Kørup, for their contributions to the data processing. B. W. R. designed the analyses of this study, performed the statistical analyses and was responsible for writing the manuscript. J. M. was responsible for the design and collection of the data in the Danish National Survey of Dietary Habits and Physical Activity. P. B. B. contributed to the statistical counselling. B. W. R., J. M., P. B. B., L. F. A. and I. T. all participated in the discussion of the results and the revision of the manuscript. The authors declare that they have no conflict of interest.

\section{References}

1. Slattery ML (2010) Analysis of dietary patterns in epidemiological research. Appl Physiol Nutr Metab 35, 207-210.

2. Tucker KL (2010) Dietary patterns, approaches, and multicultural perspective. Appl Physiol Nutr Metab 35, 211-218.

3. Newby PK \& Tucker KL (2004) Empirically derived eating patterns using factor or cluster analysis: a review. Nutr Rev 62, 177-203.

4. del Mar Bibiloni M, Martínez E, Llull R, et al. (2011) Western and Mediterranean dietary patterns among Balearic Islands' adolescents: socio-economic and lifestyle determinants. Public Health Nutr 15, 683-692.

5. Lioret S, Touvier M, Lafay L, et al. (2008) Dietary and physical activity patterns in French children are related to overweight and socioeconomic status. J Nutr 138, 101-107.

6. Craig LC, McNeill G, Macdiarmid JI, et al. (2010) Dietary patterns of school-age children in Scotland: association with socio-economic indicators, physical activity and obesity. Br J Nutr 103, 319-334.

7. Moreira P, Santos S, Padrao P, et al. (2010) Food patterns according to sociodemographics, physical activity, sleeping and obesity in Portuguese children. Int $J$ Environ Res Public Health 7, 1121-1138.

8. Oellingrath IM, Svendsen MV \& Brantsaeter AL (2011) Tracking of eating patterns and overweight - a follow-up study of Norwegian schoolchildren from middle childhood to early adolescence. Nutr J 10, 106.

9. Northstone K \& Emmett PM (2008) Are dietary patterns stable throughout early and mid-childhood? A birth cohort study. Br J Nutr 100, 1069-1076.

10. Crozier SR, Robinson SM, Godfrey KM, et al. (2009) Women's dietary patterns change little from before to during pregnancy. J Nutr 139, 1956-1963.

11. Borland SE, Robinson SM, Crozier SR, et al. (2008) Stability of dietary patterns in young women over a 2-year period. Eur J Clin Nutr 62, 119-126.

12. Bjelland M, Lien N, Grydeland M, et al. (2011) Intakes and perceived home availability of sugar-sweetened beverages, fruit and vegetables as reported by mothers, fathers and adolescents in the HEIA (HEalth In Adolescents) study. Public Health Nutr 1-10.

13. Cullen KW, Lara KM \& de Moor C (2002) Children's dietary fat intake and fat practices vary by meal and day. $J \mathrm{Am}$ Diet Assoc 102, 1773-1778.

14. Rothausen BW, Matthiessen J, Hoppe C, et al. (2012) Differences in Danish children's diet quality on weekdays v. weekend days. Public Health Nutr (epublication ahead of print version 25 May 2012).

15. Rothausen BW, Matthiessen J, Groth MV, et al. (2012) Comparison of estimated energy intake from $2 \times 24$-hour recalls and a 7-day food record with objective measurements of energy expenditure in children. Food Nutr Res $\mathbf{5 6}$ (epublication 15 February 2012).

16. Biltoft-Jensen A, Matthiessen J, Rasmussen LB, et al. (2009) Validation of the Danish 7-day pre-coded food diary among adults: energy intake $\mathrm{v}$. energy expenditure and recording length. Br J Nutr 102, 1838-1846.

17. World Health Organization (2003) Diet, Nutrition and the Prevention of Chronic Diseases. Joint WHO/FAO Expert Consultation. Geneva: WHO.

18. Patterson E, Warnberg J, Poortvliet E, et al. (2010) Dietary energy density as a marker of dietary quality in Swedish children and adolescents: the European Youth Heart Study. Eur J Clin Nutr 64, 356-363.

19. Cole T, Bellizzi M, Flegal K, et al. (2000) Establishing a standard definition for child overweight and obesity worldwide: international survey RID B-7883-2008. Br Med J 320, $1240-1243$.

20. Forrestal SG (2011) Energy intake misreporting among children and adolescents: a literature review. Matern Child Nutr 7, 112-127.

21. Eriksson L, Johansson E \& Kettaneh-Wold N (2006) Multiand Megavariate Data Analysis. Part I: Basic Principles and Applications. Umeå: Umetrics Academy.

22. Northstone K, Ness AR, Emmett PM, et al. (2008) Adjusting for energy intake in dietary pattern investigations using principal components analysis. Eur J Clin Nutr 62, 931-938.

23. Cutler GJ, Flood A, Hannan P, et al. (2009) Major patterns of dietary intake in adolescents and their stability over time. J Nutr 139, 323-328.

24. Mikkila V, Rasanen L, Raitakari O, et al. (2005) Consistent dietary patterns identified from childhood to adulthood: the cardiovascular risk in Young Finns Study. Br J Nutr 93 , 923-931.

25. Cuco G, Fernandez-Ballart J, Sala J, et al. (2006) Dietary patterns and associated lifestyles in preconception, pregnancy and postpartum. Eur J Clin Nutr 60, 364-371. 
26. Newby PK, Weismayer C, Akesson A, et al. (2006) Long-term stability of food patterns identified by use of factor analysis among Swedish women. J Nutr 136, 626-633.

27. Weismayer C, Anderson JG \& Wolk A (2006) Changes in the stability of dietary patterns in a study of middle-aged Swedish women. J Nutr 136, 1582-1587.

28. Taylor JP, Evers S \& McKenna M (2005) Determinants of healthy eating in children and youth. Can J Public Health 96, Suppl. 3, S20-S26, S22-S29.

29. Sepp H, Lennernas M, Pettersson R, et al. (2001) Children's nutrient intake at preschool and at home. Acta Paediatr 90, 483-491.

30. Garemo M, Lenner RA \& Strandvik B (2007) Swedish pre-school children eat too much junk food and sucrose. Acta Paediatr 96, 266-272.

31. Lehtisalo J, Erkkola M, Tapanainen H, et al. (2010) Food consumption and nutrient intake in day care and at home in 3-year-old Finnish children. Public Health Nutr $\mathbf{1 3}$ 957-964.

32. World Cancer Research Fund/American Institute for Cancer Research (2007) Food, Nutrition, Physical Activity, and the Prevention of Cancer: A Global Perspective. Washington DC: AICR.

33. Ledikwe JH, Blanck HM, Khan LK, et al. (2006) Lowenergy-density diets are associated with high diet quality in adults in the United States. J Am Diet Assoc 106, 1172-1180.

34. Michels KB \& Schulze MB (2005) Can dietary patterns help us detect diet-disease associations? Nutr Res Rev 18, 241-248.

35. Togo P, Heitmann BL, Sorensen TI, et al. (2003) Consistency of food intake factors by different dietary assessment methods and population groups. Br J Nutr 90, $667-678$ 